\title{
Sciendo
}

RURAL SUSTAINABILITY RESEARCH 43(338), 2020

ISSN - 2256-0939

(c) Latvia University of Life Sciences and Technologies, all rights reserved http://www.llu.Iv/en/

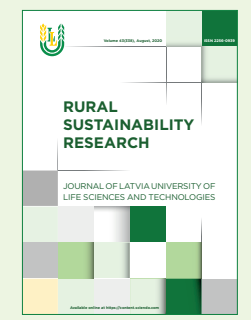

Received: 31 March 2020

Revised: 13 May 2020

Accepted: 11 June 2020

\section{Characteristics and Challenges of the Internet of Things in Entrepreneurship}

\author{
*Lasma Licite-Kurbe, Athul Chandramohan \\ Faculty of Economics and Social Development, Latvia University of \\ Life Sciences and Technologies, Jelgava, Latvia \\ ORCID ID: Lasma Licite https://orcid.org/0000-0001-7206-7608 \\ JEL code: D83, L26.
}

\begin{abstract}
The Internet of Things (IoT) is a computing concept that describes the idea of everyday physical objects being connected to the Internet and being able to identify themselves to other devices, and day by day it becomes popular in everyday life as well as in entrepreneurship. The IoT covers broad areas, including manufacturing, the health sector, agriculture, smart cities, security and emergencies among many others. The market for the industrial IoT is estimated to surpass 107 billion euros by 2021 and reach a compound annual growth rate of $7.3 \%$ as of 2020. The IoT makes an impact on all industries and provides benefits for various areas of business; however, business may be faced with some risks as well. The research aim is to analyse the benefits and risks of the IoT in entrepreneurship. The descriptive method, analysis and synthesis, the induction and deduction methods were used to achieve the aim. The research has revealed that the IoT can provide several opportunities for business in all fields of operations - marketing, logistics, accounting and human resource management. However, businesses may be faced with some challenges related to privacy and security, processing, analysis and management of data, as well as monitoring and sensing.
\end{abstract}

Key words: Internet of Things, IoT benefits, IoT risks.

\section{Introduction}

The term Internet of Things (IoT) was first mentioned in 1999 (Ashton, 2009) by characterizing the concept of radio frequency identification and its link to the Internet. Nowadays the IoT can be described as a dense network of connected physical things that are easily accessible through the Internet. The "things" in the IoT are the objects that have an IP address associated with them and have the ability to sense and transfer data over a network without human intervention. The embedded technology in the objects helps them interact with each other and with the physical environment around (Sharma \& Patel, 2017). The IoT has evolved hugely since the 1990s and in the recent years has become a reality on a massive scale and is no longer just about Internet connected devices. According to forecasts, 25 billion devices could be connected to the Internet in 2020 (Ray, 2018), and those connections facilitate data processing to analyse, manage and make intelligent decisions autonomously (Asghari, Rahmani, \& Javadi, 2018). The number connections to the IoT is likely to increase over the coming years and will continue to do so over a long period of time, exceeding the world's total population soon. There are several key factors that contributed to this expansion, some of which being expansion of networking capabilities, introduction of data analytics tools and development of new standards.

Based on IoT topicality in recent years, the IoT has gained much attention from researchers and practitioners from around the world. Different authors have analysed the definitions of the IoT (Vongsingthong \& Smanchat, 2014), the importance and application of it in different industries (Hussein, 2019) and the benefits of and challenges to the IoT (Sharma \& Patel, 2017; Yan \& Huang, 2009). The IoT holds the potential to be a game changer for digital transformation for various industries. The industrial

\footnotetext{
* Corresponding Author's email: 
revolution has already been jump started by sensors and other devices. The involvement of the IoT in various aspects of business tends to improve supply chain visibility by many folds. Manufacturing, logistics and utility industries are as of now the major implementers and benefiters from the IoT, but these will not be the only industries that will witness a deeper penetration. With the IoT, the businesses are already seeing a rise in sales of products and services by putting in value innovation and improved customer experience. Soon, for businesses to stay competitive, embracing the IoT will become a must do, and there would not be an alternative. However, even with such a massive opportunity on the rise and knowing that their business may be at stake, the majority of the companies still remain unprepared for the IoT. This could be attributed to various factors such as analysis paralysis, confusion amongst the business leaders, risks involved with the IoT and limited information about the IoT market, as there is no current market leader.

The research hypothesis: the IoT provides significant benefits in entrepreneurship. The research aim is to analyse the benefits and risks of the IoT in entrepreneurship. The following research tasks are set to achieve the aim: 1) to examine the nature and development of the IoT; 2) to analyse the benefits and risks of the IoT in entrepreneurship.

\section{Methods}

The following research methods were used to achieve the aim and perform the tasks: the descriptive method - to shape the theoretical discussion and interpret the research results based on the scientific findings and theories on IoT technology; analysis and synthesis - to examine individual problem elements and identify connections among them; induction was used to make scientific assumptions and identify causal relationships from individual elements or facts; deduction was employed to logically systematize and explain empirical data.

\section{Results and Discussion}

\section{Nature and Development of the IoT}

According to the evolution of the Internet, there could be categorized five eras: the Internet of documents (e-libraries, document based webpages), the Internet of commerce (e-commerce, e-banking and stock trading websites), the Internet of applications (Web 2.0), the Internet of people (social networks) an the IoT (connected devices) (Vankani, 2020). In scientific literature, the IoT has been attributed a variety of descriptions (Oriwoh \& Conrad, 2015). It has been described as a network (Gubbi et al., 2013; Xia et al., 2012; Hussein, 2019), a paradigm (Ning \& Liu, 2012; Ryu et al., 2012), a concept (Bari, Mani,
\& Berkovich, 2013), and an ecosystem (Asghari, Rahmani, \& Javadi, 2018) and a global network infrastructure (Vongsingthong \& Smanchat, 2014; Lupton, 2019). Within this research paper, the IoT is defined as a computing concept that describes the idea of everyday physical objects being connected to the internet and being able to identify themselves to other devices. The IoT is an Internet of three things, namely, people to people, people to things and things to things interacting through the Internet (Atzori, Iera, \& Morabito, 2010). The main characteristics of the IoT are interconnectivity, heterogeneity, unique identity, intelligence, dynamic changes, self-adapting, sensing, energy, architecture, scalability, safety and reliability.

The IoT comes with its own set of technologies which help connecting the things, retrieving the data and then communicating with other applications. The number of IoT devices is rapidly expanding. The industry analytics company Gartner estimated that in 2017, there were 8.4 billion Internet-connected things in use (Lupton, 2019). These objects include mobile devices such as smartphones, tablet computers, and wearable devices like fitness trackers and smartwatches, as well as industrial machinery and transport systems. Moreover, the influence of the IoT on the Internet and the economy are striking, with some anticipating as many as 100 billion connected IoT devices and a global economic impact of more than 10 trillion euros by 2025 (Vankani, 2020).

The IoT covers broad areas, including manufacturing or the industrial sector, the health sector, agriculture, smart cities, security and emergencies among many others. The market for the industrial IoT is estimated to surpass 107 billion euros by 2021 and reach a compound annual growth rate of $7.3 \%$ as of 2020 . Also, by 2020 it is estimated that the manufacturing and logistics industry would be spending a sum of 35 billion euros each for the IoT platforms and services separately (Columbus, 2018).

Taking into account the topicality of the IoT, the investments made in the IoT are estimated to double by the year 2020, and the industries that would be making the largest investments in this market are manufacturing, logistics and utilities (Statista, 2020). The IoT that is meant for consumer services closely follows when it comes to investments. In the manufacturing segment, the operations demand for more spending, compared with the other aspects. In the logistics segment, freight monitoring is and would be the call for the investments made. When it comes to the utilities segment, the investments would be made mostly in the grids for electricity and gas. A comparison of the investments made in 2015 with the forecasted investment for the year 2020 for the various segments is shown in Figure 1. 


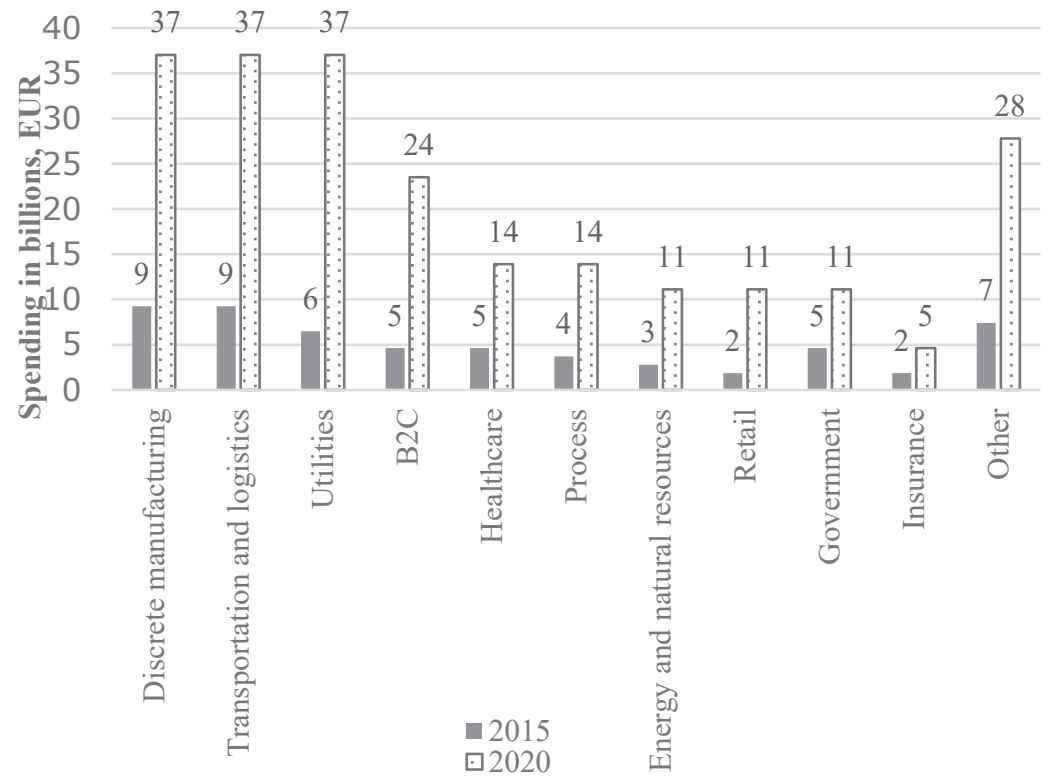

Source: authors' construction based on Statista 2020.

Figure 1. Spending on the IoT worldwide in 2015 and 2020, billion EUR.

In terms of investments made region wise, the major share of spending is done in the Asia Pacific region (compounded annual growth rate - CAGR $7.6 \%$ in 2020), followed by North America (6.5\%) and Western Europe (6.3\%). Even though every region has started with implementing the IoT, it is the developed regions that are maintaining a lead and are estimated to continue doing so. The investments made in traditional information, communications and technology can be mentioned as one of the indicators of the relative proportions that can be expected to be seen in the IoT market; however, it is not the only driver of how the regions are expected to make progress relative to each other (Lund et al., 2014).
The European market is growing owing to an increase in the number of IoT devices. The market share of the IoT in Europe in 2014 and 2020 broken down by country is shown in Figure 2.

It could be concluded that Germany is estimated to have the largest IoT market share in Europe in 2020. In total, the top six countries make up $75 \%$ of the European IoT market. In the coming years, the IoT market is expected to grow in all the European countries. To be more specific, the Western European countries which also happen to be the major investors in the IoT hold the leading positions when it comes to market position. IoT connections are growing at a fast pace in Europe, and this growth is attributed

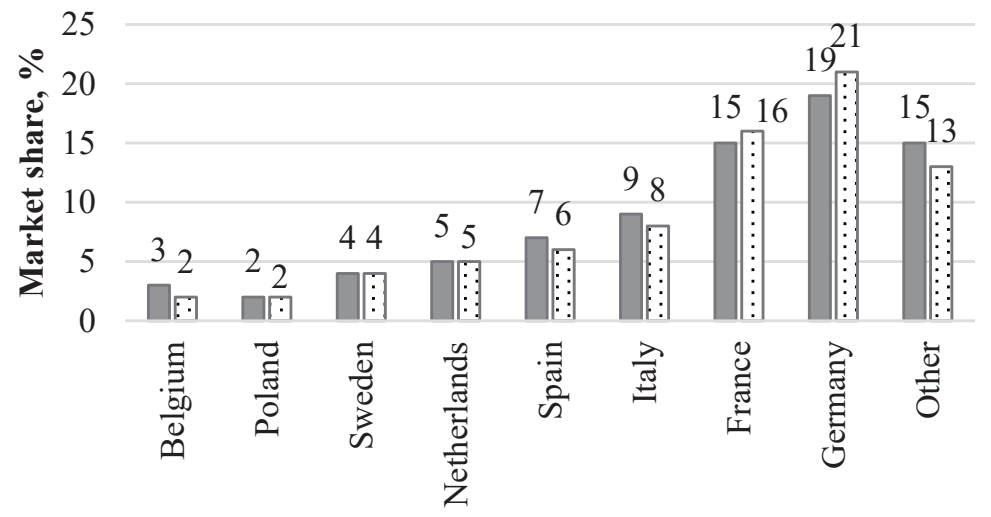

$\square 2014 \square 2020$

Source: authors' construction based on Statista 2020.

Figure 2. IoT market share in European countries in 2014 and 2020, \%. 
to quicker acceptance of the IoT in several verticals (Brunsden, 2017).

As it is stated in scientific literature, the IoT is an asset for the core for any business to guide it through a phase of digital transformation by helping the industries to raise the operational efficiency and to have incremental growth. The organizations are working towards setting up use cases that could help with data extraction and data transfer.

Opportunities and Risks of the IoT in Entrepreneurship

The IoT makes a way for a lot more opportunities than what is being put into use today. In order for businesses to be able to pursue these opportunities, businesses need infrastructure that can support the IoT. Even though the IoT sounds as a term that matters only to programmers or business that are inclined more to technology, however, in reality it makes an impact on all industries and provides benefits for different departments of the company.

Benefits. There are a wide range of possibilities that the IoT can provide for entrepreneurs. First and foremost, the IoT comes up with new data sets, and this could be developed further into information. It is very important in logistics. With proper information, the supply chain can be made to operate more desirably and also improve the efficiency. Since the data are collected digitally, there would be larger amounts of data available and at a faster rate. The routes for the logistics units can be optimized so that there is less distance covered while having no loads (Yan \& Huang, 2009). Also, at any given point of time, the state of machineries that are critical can be monitored thanks to the status data and the trend data that are available (Yan \& Huang, 2009). The data can also be used to identify any possibilities of an imminent issue or failure. Therefore, preventive maintenance can be carried out at the earliest time in such a way it does not affect the production (Yan \& Huang, 2009). As stated by M.J. Vankani (2020), the things can be easily found if they are lost or stolen.

Let alone machineries, even raw materials as well as final products can communicate through the IoT. Now it is possible to know how much of what is available. It is even possible to locate a particular product, e.g. whether it is in a warehouse or maybe in a retail store or even in motion as in a truck (Yan \& Huang, 2009). As a result, the data from the supply chain also help the accounting department to see the properties, resources and inventory data from the supply chain (Yan \& Huang, 2009).

The IoT can also, in a way, help with the marketing of products. The IoT can establish a point of link between the selling and the customer data. This means it can track the sales of any product. The consumption pattern of these products by the consumer can be monitored. Hence, the forecasts for the demand and the sales can be better understood and presented and accordingly the marketing strategies can be improved. Apart from this, the design for the products can also be augmented (Yan \& Huang, 2009).

The most important benefits that are achieved by IoT applications are monitoring and consequently immediate decision making for efficient management (Asghari, Rahmani, \& Javadi, 2018).

The IoT can be useful for the human resource department as well. With the help of data from the employees received via wearables, the human resource department could set up a promisingly positive work culture, as now it is possible that the productivity of the employees, the communication and behaviours could be assessed (Vivekananth, 2016). Also, there is more efficient and quicker communication that would happen, and exchanging ideas would become much easier. This is how the IoT will improve employee effectiveness and gives the employees a better experience at the workplace. The wellbeing of the employees can also be monitored and analysed with the help of IoT technology. The wearable devices help with tracking the health of employees and as such measures could be initiated in case the information is not a pleasant one. The IoT helps to bring out a digital work culture (Waber, 2013). The employee behaviour can also be monitored with the help of IoT technology at the workplace. Most of the companies have a badge wearing system, which could be used for entry into the workplace or registering the attendance. These badges could be used as a sociometric device, which could give insight into the employee's behaviour and also stress levels by monitoring the employee's voice modulation levels or heart beat rates. The tone, with which the employees make conversation, can also be monitored, and this can, in a way, be used to analyse the satisfaction of the employee at the workplace. It can also track the employee's position at any given point of time. In the logistics industry, this can be used to track the movement of drivers, and the idle time can be reduced between each delivery (Sullivan, 2013).

A major aspect or role for the human resource department is the recruitment process. The IoT can help with measuring the responsiveness of the person being recruited and could make way for a much easier and less stressful recruitment process. The candidates could be put into a virtual world by using the virtual reality tools, and their responsiveness or their instinctive thinking can be tracked by using the wearable devices on them. Also, the candidates who clear the recruitment can also be given a taste of how the work environment would look like using this technology (Sullivan, 2013). 
Risks. Even though the current IoT enabling technologies have greatly improved in the recent years, there are still numerous risks and challenges that require attention (Hussein, 2019).

On the one hand, these data are proven to be a saviour while on the other, too much data without an action plan could work in a negative way. The requirements for the business should be the core, and all other things should work towards it. The intensity of collecting data should not be mistaken to be directly proportional to the improvement of the quality of the processes. This means that if a process is not worked out properly from start and is giving negative returns, the use of the data and the IoT solution would only worsen the problem and maybe take it to the next level (Tao, Cheng, \& Li, 2014).

Security and privacy of data in the IoT is a challenge (Vankani, 2020). Unlike in the environment of the server, mobile computing where the security is still not up to the mark, it is even more challenging when it comes to the IoT. The main reason for this would be the fact that industries implementing the IoT solutions often work in a different standalone network, with reliability being the top on the list of priorities followed by security. When the industrial network is connected to the IoT, it becomes open to anyone. The vendors for the IoT have not been working on the security aspect. Security for the IoT network should be made equally a matter of concern for cyber security experts as it is for the Internet (Wang \& Ranjan, 2015).

Also, regarding human resources, there are several challenges. One of the main challenges be the unwillingness of the employees in giving away data about themselves. The employees are in a way uncertain if the monitoring data could be used against them at some point. Also, there is a doubt amongst employees if the employers are capturing the information with the employees being aware of it. This could also lead to frustration amongst the employees (Peppet, 2014). Consider a situation wherein a logistics company where the driver's movements are monitored to improve driving efficiency and minimize distance and cost. As such, the driver is constantly given instructions when to brake, when to reverse, which turn to take, thereby eventually minimizing the intellectual inputs for the driver. This would ultimately stress out the driver.

It should be kept in mind that the IoT technology thrives on data, and the technology would only make sense if the data are available in enough quantity and are valid. If the data generated are insufficient, it could lead to making misleading decisions, and if the data are too much, it could waste the time and effort of the managers to come up with ways to sort and act upon the data. To get the right quality and quantity of data, the collection or gathering needs to be done for a prolonged period. The workers' task may vary with time and also their behaviours and therefore the data collection needs to be done for as long as it is permissible and possible (Vivekananth, 2016).

Another challenge posed is the collection of data via many systems within the same organization. This could lead to redundant data. There should be a proper system in place to ensure what is needed is collected and managed properly. Since there is a large number of devices that can now be connected within the organization, there is always a chance for security breach to happen. This could be controlled by authorizing the data retrieving and sharing process with the organization. The organization should have a proper transparent process and procedures in place to have the data secured, managed properly and abide by the standards already set (Peppet, 2014).

The human resources should be well aware of the data that could be used and that could not be used. It is very important that the employees themselves know what data are being used and for what purposes so that they do not feel that their privacy is being compromised. Also, the human resources department should have the permission from the employees to let them being tracked. It is also the human resource department's responsibility to make sure that every employee are on the same page when it comes to deploying the technology and also that they understand the implications and are willing to adapt (Peppet, 2014).

The IoT undoubtedly has a great impact on how the organization's human resources function. It would play a major role in the organization's performance and would put it on the path for being efficient. There is a higher possibility for a better work culture and environment now. The human resource department should develop a way in which the brain power of the people within the organization could be used to fuel the IoT and bridge the gap between the goal achieved by technology and the goal achieved by the people. There needs to be a balance between what the organization needs and how the workforce goals could help to achieve it without being caught up with the privacy issues and the different lifestyles, thereby rectifying the problems in the working environment and henceforth making the organization have a competitive edge (Fecheyr-Lippens, Schaninger, \& Tanner, 2015).

The main benefits and risks of implementing the IoT in the business are summarized in Table 1.

As it can be seen in Table 1, the IoT offers numerous benefits to the varied range of diverse areas in entrepreneurship. This could mean that the entrepreneurs with a creative mind-set, urge to excel and having a risk taking attitude could witness 
Benefits and risks of implementing the IoT in entrepreneurship

\begin{tabular}{|c|c|c|}
\hline \multicolumn{2}{|r|}{ Benefits of IoT } & Risks \\
\hline Marketing & $\begin{array}{l}\text { - Effective link between the selling and the } \\
\text { customer data. } \\
\text { - The consumption pattern of products by } \\
\text { the consumer can be monitored. } \\
\text { - Advanced functionalities. } \\
\text { - More engagement with the customers. }\end{array}$ & $\begin{array}{l}\text { - Customer data privacy issues. } \\
\text { - Creating proper experience for customers } \\
\text { without being annoying. }\end{array}$ \\
\hline Accounting & $\begin{array}{l}\text { - Easier access to client information. } \\
\text { - Better business planning. } \\
\text { - Improve accuracy of budgets. } \\
\text { - Improve forecasting. }\end{array}$ & $\begin{array}{l}\text { - Corrupt data could put client at risk. } \\
\text { - Different privacy policies for different } \\
\text { companies. }\end{array}$ \\
\hline Logistics & $\begin{array}{l}\text { - Optimum asset utilization. } \\
\text { - } \text { Easier material handling. } \\
\text { - } \text { Better warehousing and inventory control } \\
\text { practices. } \\
\text { - } \text { Easier fleet monitoring. } \\
\text { - Faster tracking and tracing. } \\
\text { - Predictive maintenance of equipment. }\end{array}$ & $\begin{array}{l}\text { - Connectivity issues among the large } \\
\text { number of devices. } \\
\text { - Huge amount of data needs to be processed. }\end{array}$ \\
\hline $\begin{array}{l}\text { Human } \\
\text { resources }\end{array}$ & $\begin{array}{l}\text { - Increasing use of wearables. } \\
\text { - Evaluating employee productivity. } \\
\text { - Efficient and quicker communication. } \\
\text { - } \text { be mployee behaviour and well-being can } \\
\text { - Flexible working environment. } \\
\text { - Measuring responsiveness of new } \\
\text { recruits. }\end{array}$ & $\begin{array}{l}\text { - Unwillingness of employees to give data. } \\
\text { - Misleading data would waste management's } \\
\text { time and effort. } \\
\text { - Redundant data. }\end{array}$ \\
\hline Management & - Helps in decision making process & $\begin{array}{l}\text { - If the data generated are insufficient, it } \\
\text { could lead to making misleading decisions. } \\
\text { - If the data are too much, it could waste the } \\
\text { time and effort of the managers to come } \\
\text { up with ways to sort and act upon the data. }\end{array}$ \\
\hline
\end{tabular}

Source: authors' compilation based on Yan \& Huang., 2009; Vivekananth, 2016; Sullivan, 2013; Tao, Cheng, \& Li, 2014; Vankani, 2020; Wang \& Ranjan, 2015; Peppet, 2014; Fecheyr-Lippens, Schaninger, \& Tanner, 2015.

opportunities to capitalize on this and become leaders of the industry. This could also help with developing new revenue sources and having a new business line setup all together and with the possibility of the IoT to be deployed in every step of business, the likely gains would be huge.

\section{Conclusions, Proposals, Recommendations}

1) The IoT plays a central role in entrepreneurship, and it has potential to increase the availability of information and is likely to transform enterprises in virtually every industry around the world.

2) The concept of IoT has been attributed a variety of descriptions. It has been defined as a network, a paradigm, a concept, an ecosystem and a global network infrastructure. Within this research paper, the IoT is defined as a computing concept that describes the idea of everyday physical objects being connected to the Internet and being able to identify themselves to other devices.

3) The IoT covers broad areas, including manufacturing or the industrial sector, the health sector, agriculture, smart cities, security and emergencies among many others. The market for the industrial IoT is estimated to surpass 107 billion euros by 2021 and reach a compound annual growth rate of $7.3 \%$ as of 2020. The IoT makes an impact on all industries and provides benefits for various areas of business. 
4) The IoT can provide several opportunities for business in any field of operations - marketing, logistics, accounting, human resources and management of the company. In human resource management, the IoT can be useful in evaluating employee productivity, provide quick communication and monitor employee behaviour and well-being. In the marketing field, it can be used to provide effective engagement and monitor customers, while in accounting it provides easier access to the various types of information and financial planning. In logistics, it provides optimum asset utilization, warehouse and inventory control practises and faster tracking and tracing.

5) There are numerous risks and challenges that require attention to the use of the IoT. Mainly these risks related to privacy and security, processing, analysis and management of data, as well as monitoring and sensing.

\section{References}

Asghari, P., Rahmani, A.M., Javadi, H.H.S. (2018). Internet of Things applications: A Systematic Review. Computer Networks, Volume 148, pp. 241-261.

Ashton, K. (2009). That 'Internet of Things' Thing: In the Real World Things Matter More than Ideas RFID Journal, Volume 22, Issue 7, pp. 97-114.

Atzori, L., Iera, A., Morabito, G. (2010). The Internet of Things: A Survey. Computer Networks, Volume 54, Issue 15, pp. 2787-2805.

Bari, N., Mani, G., Berkovich, S. (2013). Internet of Things as a Methodological Concept. Fourth International Conference on Computing for Geospatial Research and Application, San Jose, CA, pp. 48-55.

Brunsden, J. (2017). Europe Gears up to Play Pivotal Role in 'Internet of Things'. Retrieved March 20, 2020 from https://www.ft.com/content/ a8fdd43a-d5bd-11e7-8c9a-d9c0a5c8d5c9.

Columbus, L. (2018). 10 Charts that will Challenge Your Perspective of IoT's. Retrieved March 20, 2020 from https://www.forbes.com/sites/ louiscolumbus/2018/06/06/10-charts-thatwill-challenge-your-perspective-of-iotsgrowth/\#ac2d22b3ecce.

Fecheyr-Lippens, B., Schaninger, B., Tanner, K. (2015). Power to the New People Analytics. McKinsey Quarterly, Volume 51, Issue 1, pp. 61-63.

Gubbi, J., Buyya, R., Marusic, S., Palaniswami, M. (2013). Internet of Things (IoT): A Vision, Architectural Elements, and Future Directions. Future Generation Computer Systems, Vol. 29, pp. $1645-1660$.
Hussein, A.H. (2019). Internet of Things (IOT): Research Challenges and Future Applications. International Journal of Advanced Computer Science and Applications, Volume 10, Issue 6, pp.77-82.

Lund, D., MacGillivray, C., Turner, V., Morales, M. (2014). Worldwide and Regional Internet of Things (IoT) 2014-2020 Forecast: A Virtuous Circle of Proven Value and Demand. International Data Corporation (IDC). Retrieved March 20, 2020 from http://branden.biz/wp-content/ uploads/2017/06/IoT-worldwide_regional_20142020-forecast.pdf.

Lupton, D. (2019). The Internet of Things: Social Dimensions. Sociology Compass, January 13. Retrieved March 20, 2020 from https:// www//C:/Users/Lietotajs/Downloads/Lupton2020InternetofThings-socialdimensions.pdf.

Ning, H., Liu, H. (2012). Cyber-Physical-Social Based Security Architecture for Future Internet of Things. Internet of Things, Vol. 2, pp. 1-7.

Oriwoh, E., Conrad, M. (2015). 'Things' in the Internet of Things: Towards a Definition. International Journal of Internet of Things, Volume 4, Issue 1, pp. 1-5.

Peppet, S.R. (2014). Regulating the Internet of Things: First Steps Toward Managing Discrimination, Privacy, Security and Consent. Texas Law Review, Volume 93, Issue 1, pp. 85-179.

Ray, P.P. (2018). A Survey on Internet of Things Architectures. Journal of King Saud University Computer and Information Sciences, Volume 30, Issue 3, pp. 291-319.

Ryu, M. W., Kim, J., Lee, S.S., Song, M.H. (2012). Survey on Internet of Things: Toward Case Study. Smart Computing Review, Volume 2, Issue 3, pp. 125-137.

Sharma, S., Patel, H.B. (2017). Internet of Things: Definition, Applications, Issues and Future Prospective. International Journal on Recent and Innovation Trends in Computing and Communication, Volume 5, Issue 8, pp. 113-116.

Statista (2020). Spending on Internet of Things worldwide by vertical in 2015 and 2020 . Retrieved March 20, 2020 from: www.statista. com/statistics/666864/iot-spending-by-verticalworldwide/

Sullivan, J. (2013). How Google is Using People Analytics to Completely Reinvent HR. Retrieved March 20, 2020 from https:/www.tlnt.com/howgoogle-is-using-people-analytics-to-completelyreinvent-hr/.

Tao F., Cheng Y., Li B.H. (2014). CCIoT-CMfg: Cloud Computing and Internet of Things-based Cloud Manufacturing Service System. IEEE 
Transactions on Industrial Informatics, Volume 10, Issue 2, pp. 1435-1442.

Vankani, M. (2020). Internet of Things - Future of World. Retrieved March 20, 2020 from https:// www.researchgate.net/publication/339874025 INTERNET_OF_THINGS_FUTURE_OF_ WORLD.

Vivekananth, P. (2016). The Impact of Internet of Things (IoT) in Human Resource Management. IPASJ International Journal of management, Volume 4, issue 9, September 2016, pp. 001-003. Vongsingthong, S., Smanchat, S. (2014). Internet of Things: A review of Applications and Technologies. Suranaree Journal of Science and Technology, Volume 21, Issue 4, pp. 359-374.
Waber, B. (2013). People Analytics: How Social Sensing Technology will Transform Business and What It Tells Us About the Future of Work. United States of America: FT Press Analytics. p. 240.

Wang, L., Ranjan, R. (2015). Processing Distributed Internet of Things Data in Clouds. IEEE Cloud Computing, Volume 2, Issue 1, pp. 76-80.

Xia, F., Yang, L.T., Wang, L., Vinel, A. (2012). Internet of Things. International Journal of Communication Systems, Volume 25, Issue 9, pp.1101-1102.

Yan, B., Huang, G. (2009). Supply Chain Information Transmission based on RFID and Internet of Things. ISECS International Colloquium on Computing, Communication, Control, and Management, Volume 4, pp. 166-169. 